\title{
Correlation between penile cuff test and pressure-flow study in patients candidates for trans-urethral resection of prostate
}

\author{
Daniele Bianchi ${ }^{*}$, Angelo Di Santo ${ }^{2}$, Gabriele Gaziev ${ }^{1}$, Roberto Miano ${ }^{3}$, Stefania Musco ${ }^{4}$, Giuseppe Vespasiani ${ }^{3}$ \\ and Enrico Finazzi Agrò ${ }^{3}$
}

\begin{abstract}
Background: Aim of this study was to make a comparison between penile cuff test (PCT) and standard pressure-flow study (PFS) in the preoperative evaluation of patients candidates for trans-urethral resection of prostate (TURP) for benign prostatic obstruction (BPO).

Methods: We enrolled male patients with lower urinary tract symptoms candidates for TURP. Each of them underwent a PCT and a subsequent PFS. A statistical analysis was performed: sensitivity (SE), specificity (SP), positive predictive value (PPV), negative predictive value (NPV), likelihood ratio and ratio of corrected classified were calculated. Fisher exact test was used to evaluate relationships between $P C T$ and maximal urine flow $\left(Q_{\max }\right)$ : a $p$-value $<0.05$ was considered statistically significant.

Results: We enrolled 48 consecutive patients. Overall, at PCT 31 patients were diagnosed as obstructed and 17 patients as unobstructed. At the subsequent PFS, 21 out of 31 patients diagnosed as obstructed at PCT were confirmed to be obstructed; one was diagnosed as unobstructed; the remaining 9 patients appeared as equivocal. Concerning the 17 patients unobstructed at PCT, all of them were confirmed not to be obstructed at PFS, with 10 equivocal and 7 unobstructed. The rate of correctly classified patients at PCT was $79 \%$ (95\%-Cl 65\%-90\%). About detecting obstructed patients, PCT showed a SE of $100 \%$ and a SP of $63 \%$. The PPV was $68 \%$, while the NPV was $100 \%$.

Conclusions: PCT can be an efficient tool in evaluating patients candidates for TURP. In particular, it showed good reliability in ruling out BPO because of its high NPV, with a high rate of correctly classified patients overall. Further studies on a huger number of patients are needed, including post-operative follow-up as well.
\end{abstract}

Keywords: Bladder isovolumetric pressure, Non-invasive urodynamics, Penile cuff test, Prostate, Trans-urethral resection of prostate

\section{Background}

The role of urodynamics (UD) in the diagnosis of benign prostate obstruction (BPO) has been intensively investigated [1,2].

In clinical practice, when required, a proper evaluation and quantification of BPO is performed by invasive UD, in particular pressure-flow study (PFS) [1].

Over the last two decades, some alternative, less invasive tests have been proposed [3], based on equipment

\footnotetext{
* Correspondence: danielebianchimail@yahoo.it

${ }^{1}$ School of Specialization in Urology, University of Rome Tor Vergata, Viale Oxford, 81-00133 Rome, Italy

Full list of author information is available at the end of the article
}

consisting of an external condom catheter [4], an intraurethral device [5] or an inflatable cuff around the penis penile cuff test (PCT) - with inflation-deflation cycles [6].

Instead of the direct intravesical sampling used in PFS, non-invasive UD aims to give information about bladder pressure by evaluating the equal urine pressure either along the urethra (in penile cuff), or at the external meatus (in external condom catheter).

In the PCT with inflation-deflation cycles [6], the pressure needed to stop the flow $\left(p_{\text {cuff }}\right)$ represents the bladder isovolumetric pressure (BIP) e.g. the bladder pressure during an isovolumetric contraction. This pressure is detected by a cuff placed around the penis before micturition [6]. 
The cuff is automatically inflated during the voiding phase, in order to stop urine flow, and then deflated again. The inflation-deflation cycle is repeated several times during a single micturition, thus allowing to correctly assess BIP (see Figure 1).

PCT results can be plotted on the nomogram proposed by Griffiths [7] which is designed on a cartesian plane with maximal urine flow $\left(Q_{\max }\right)$ on the $x$-axis and $p_{\text {cuff }}$ on $y$ axis, with an ascending straight line, with $y$-intercept equal to $80 \mathrm{~cm} \mathrm{H}_{2} \mathrm{O}$, separating obstructed from non-obstructed patients.

Recently, a new prototype of PCT has been proposed [8], using an automatically controlled inflatable cuff which detects bladder voiding pressure at constant low urine flow instead of inflation-deflation cycles.

The purpose of this study was to compare the data of PCT with inflation-deflation cycles with those of a standard PFS in patients candidates for trans-urethral resection of prostate (TURP).

\section{Methods}

Male patients who previously received indication to undergo a TURP in our or in a different center were included. Indication for TURP had been made on referral urologist opinion, generally on the basis of the presence of lower urinary tract symptoms (LUTS) and a reduced flow rate, independently by other aspects as prostate volume and alpha-blockers effectiveness.

A urine sample for urine culture was collected by spontaneous micturition within 7 days before the tests in order to rule out possible infections. Exclusion criteria were diabetes mellitus, any neurological disease, use of drugs impairing bladder contractility or impacting on lower urinary tract function, an indwelling bladder catheter over the previous six months, presence of urinary tract infection, suspect of malignancies.

Approval of the study by Ethics Committee of Policlinico Tor Vergata was obtained, and all patients signed a written informed consent to be included. For each patient, we

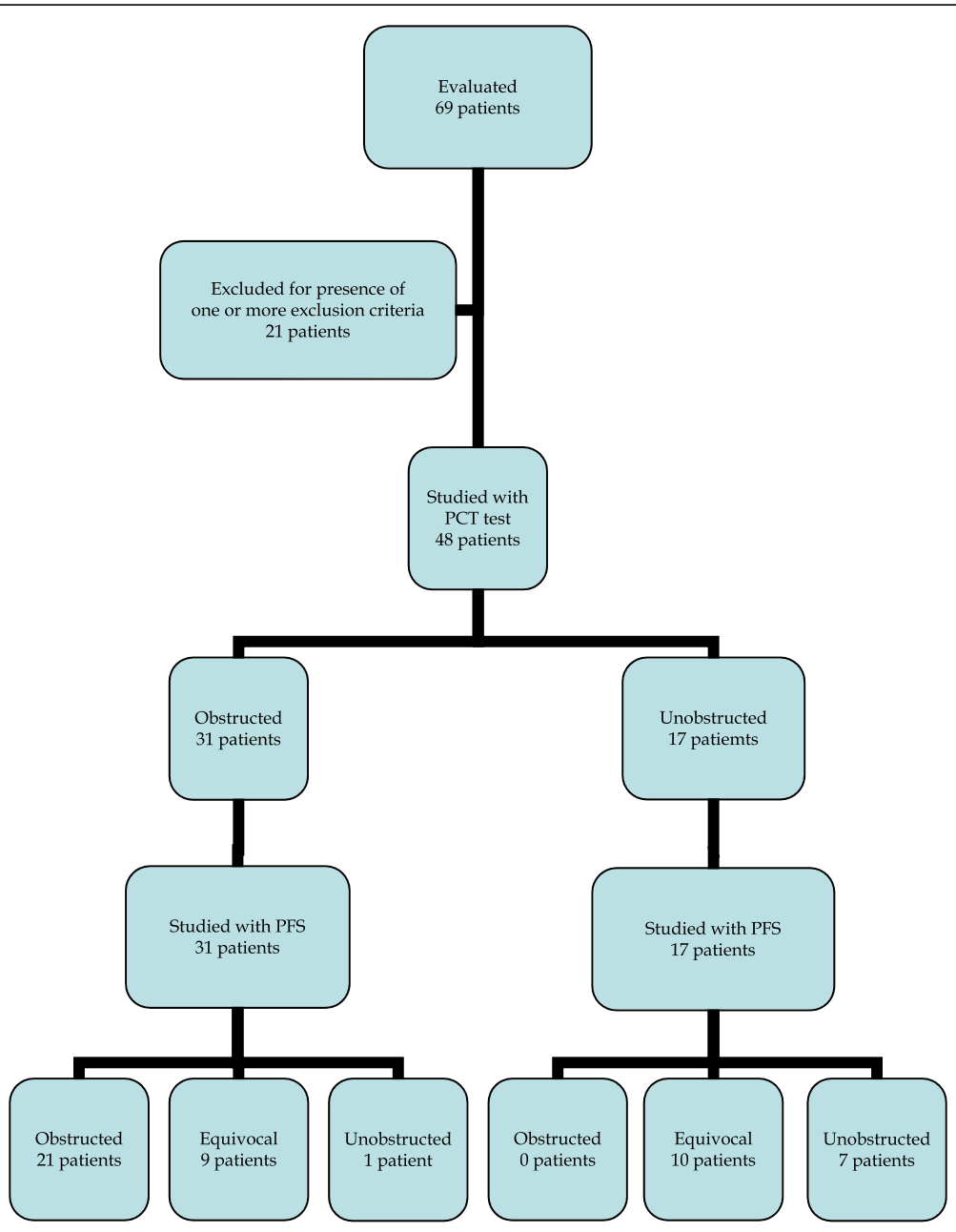

Figure 1 The principal of the test is similar to bladder pressure measurement. A small cuff is placed around the penis. When micturition has commenced, the cuff is inflated. The cuff pressure required to stop flow should equal bladder pressure. $\mathrm{p}$ iso: Isovolumetric pressure. 
performed a PCT followed by a subsequent PFS and both procedures were conducted by the same urodynamicist.

PCT was performed by Mediplus CT3000 Cuff Machine which allows multiple inflation-deflation cycles during a single micturition, getting several BIP measurements.

The patients were instructed to perform a micturition without abdominal straining.

For each inflation cycle we applied the exclusion rules proposed by Drinnan et al. [9], thus a cycle was immediately excluded in case of one of the following conditions:

- No flow recovery after cuff deflation, meaning that the micturition ended during the last cycle, so the cuff pressure could have been not responsible for urine flow stop;

- There was an 'erratic' flow trace, which could be related to straining or maybe to contractions by the pelvic floor or membranous urethra;

- The urine flow was not interrupted at the device maximum pressure, which is set at $200 \mathrm{~cm} \mathrm{H}_{2} \mathrm{O}$ for safety reasons. This situation is associated with highly contractile bladder.

Furthermore, we repeated any test showing a total bladder volume less than $150 \mathrm{~mL}$.

PFS was performed by a urodynamic equipment (Life-Tech ${ }^{\circ}$, Stafford, TX, USA) with water-filled bladder catheter and rectal balloon (Life-Tech', Stafford, TX, USA), after a filling phase with non-physiological filling rate $(30-50 \mathrm{~mL} / \mathrm{s})$.

The examination was conducted according to the International Continence Society recommendations $[10,11]$.

PFS data were plotted on the Abrams-Griffiths modified nomogram [12,13], while PCT results were plotted on the nomogram proposed by Griffiths [7].

For each of two categories - obstructed versus nonobstructed - patients were subdivided into two subgroups according to their $Q_{\max }$, with a threshold of $10 \mathrm{~mL} / \mathrm{s}$ [14], in order to evaluate if $Q_{\max }$ was able to improve accuracy.

Sensitivity (SE), specificity (SP), positive predictive value (PPV), negative predictive value (NPV), likelihood ratio and ratio of corrected classified were calculated.

In order to assess accuracy of estimated value, 95\% confidence interval $(95 \%-\mathrm{CI})$ was calculated for SE, SP, PPV, NPV and ratio of corrected classified.

Fisher exact test was used to evaluate relationships between PCT and $Q_{\max }$ : a $p$-value $<0.05$ was considered statistically significant.

Software Stata 13.0 (College Station ${ }^{\circ}$, Texas) was used for all analysis.

Results have been reported according to Standards for Reporting of Diagnostic accuracy (STARD) flowchart [15].
The research was carried out in compliance with the Helsinki Declaration - Ethical Principles for Medical Research Involving Human Subjects.

\section{Results}

We enrolled 48 consecutive male patients - mean age $61.5 \pm 13.1$ years.

On uroflowmetry, median $Q_{\max }$ was $11.6 \mathrm{~mL} / \mathrm{s}$ (range 4.0-25.0 $\mathrm{mL} / \mathrm{s}$ ), with a median post-void residual urine volume (PVR) of $42 \mathrm{~mL}$ (range $0-430 \mathrm{~mL}$ ) detected by ultrasound scan. PSA mean value was $2.35 \mathrm{ng} / \mathrm{mL}$ (range 0.80-4.10 ng/mL).

No adverse events occurred during or after the tests.

Overall, at PCT 31 patients were diagnosed as obstructed and 17 patients as unobstructed on Griffiths nomogram [7].

On the subsequent PFS, according to Abrams-Griffiths nomogram [12,13], 21 out of 31 patients diagnosed as obstructed at PCT were confirmed to be obstructed; one was diagnosed as unobstructed; the remaining 9 patients appeared as equivocal.

Concerning the 17 patients unobstructed at PCT, all of them were confirmed not to be obstructed on PFS, with 10 equivocal and 7 unobstructed (see Table 1 and Figure 2 for STARD flow-chart).

The rate of correctly classified patients at PCT was 79\% (95\%-CI 65\%-90\%).

About pressure measurements, overall at PCT we obtained a mean $p_{\text {cuff }}$ equal to $133.75 \mathrm{~cm} \mathrm{H}_{2} \mathrm{O}$ (SD $33.45 \mathrm{~cm}$ $\mathrm{H}_{2} \mathrm{O}$ ), while at PFS we had a mean detrusorial pressure at $Q_{\max }$ flow equal to $52.69 \mathrm{~cm} \mathrm{H}_{2} \mathrm{O}$ (SD $21.94 \mathrm{~cm} \mathrm{H}_{2} \mathrm{O}$ ).

Focusing on obstructed patients, at PCT we had a mean $p_{\text {cuff }}=157.00 \mathrm{~cm} \mathrm{H}_{2} \mathrm{O}$ (SD $26.83 \mathrm{~cm} \mathrm{H}_{2} \mathrm{O}$ ), while at PFS the mean detrusorial pressure was $74.00 \mathrm{~cm} \mathrm{H}_{2} \mathrm{O}$ (SD $14.13 \mathrm{~cm} \mathrm{H}_{2} \mathrm{O}$ ).

With regard to the further subdivision according to $Q_{\max }, 15$ patients out of the 31 obstructed at PCT showed a $Q_{\max }<10 \mathrm{~mL} / \mathrm{s}$, with the other 16 patients having a $Q_{\max } \geq 10 \mathrm{~mL} / \mathrm{s}$.

On the other hand, among the 17 unobstructed patients on PCT, we had 5 with a $Q_{\max }<10 \mathrm{~mL} / \mathrm{s}$ and 12 with a $Q_{\max } \geq 10 \mathrm{~mL} / \mathrm{s}$.

Patients categorization into subgroups according to their $Q_{\max }$ greater or less than $10 \mathrm{~mL} / \mathrm{s}$ did not produce a further improvement of PCT ability to diagnose BPO (Fisher exact test, $p=0.2362$ ).

Table 1 Results of penile cuff test (PCT) compared with pressure-flow studies (PFS)

\begin{tabular}{lccc}
\hline & PFS obstructed & PFS Unobstructed/Equivocal & Total \\
\hline $\begin{array}{l}\text { PENILE CUFF } \\
\text { obstructed }\end{array}$ & 21 & 10 & 31 \\
$\begin{array}{l}\text { PENILE CUFF } \\
\text { unobstructed }\end{array}$ & 0 & 17 & 17 \\
Total & 21 & 27 & 48 \\
\hline
\end{tabular}




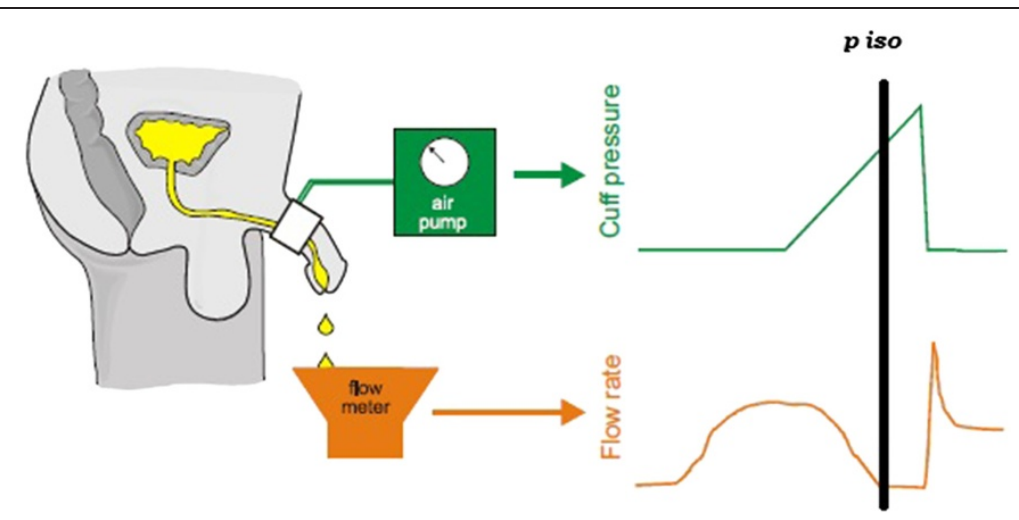

Figure 2 Results according to Standards for Reporting of Diagnostic accuracy (STARD) flow-chart. PCT: Penile Cuff Test. PFS: Pressure-Flow Studies.

About detecting obstructed patients, PCT showed a SE of $100 \%(95 \%-C I \quad 84-100 \%)$ and a SP of $63 \%(95 \%-C I$ $42-81 \%)$, with a positive likelihood ratio of 2.7 (95\%-CI 1.65-4.42). The PPV was 68\% (95\%-CI 49-83\%), while the NPV was $100 \%$ (95\%-CI $80-100 \%)$. Results are summarized in Table 2.

\section{Discussion}

Over the last century, a simple evaluation of PVR has been proposed as an appealing tool for diagnosing BPO. Nevertheless, a huge PVR may be due to an impaired detrusor contractility (IDC) [16]. In fact, it has been pointed out that up to one half of unobstructed patients with LUTS could have elevated PVR, while up to one forth of severely obstructed patients could show no PVR [1].

Thus, the association between elevated PVR and $\mathrm{BPO}$ is not strong enough to be used as a useful clinical tool [17].

In some papers, the role of uroflow trace has been investigated as well, but no reliable relation between its profile and BPO was found out [18].

Some Authors have shown that uroflowmetry could be able to assess the presence of BPO in the vaste majority of patients with $Q_{\max }$ less than $10 \mathrm{~mL} / \mathrm{s}$, with a progressively decreasing rate of $\mathrm{BPO}$ in case of $\mathrm{Q}_{\max }$ major than $10 \mathrm{~mL} / \mathrm{s}[1,2,14]$.

Accordingly, European Association of Urology guidelines have considered PFS as an optional test before surgery for $\mathrm{BPO}$, usually indicated in the preoperative evaluation of patients showing a $Q_{\max }>15 \mathrm{~mL} / \mathrm{s}$ [19].

Conversely, $25-30 \%$ of men with decreased $Q_{\max }$ at uroflowmetry are unobstructed [1]. Indeed, decreased uroflow can result from either impaired detrusor contractility (IDC) or BPO; thus, only detrusor pressure measurement is able to distinguish between those conditions $[18,20]$.

Furthermore, there are no tips on uroflowmetry trace shape that allows a distinction between BPO and IDC [18]; on the other hand, a normal uroflow test does not rule out BPO [20].

As a consequence, PFS still represents the gold standard for a proper evaluation of BPO in male patients, above all when an IDC is suspected [1].

In clinical practice, the nomogram proposed by Abrams and Griffiths for the diagnosis of obstruction in males at PFS has been widely used [16].

A further nomogram proposed by Abrams [13] aims to give a more accurate patients categorization by the

Table 2 Results of penile cuff test (PCT) compared with pressure-flow studies (PFS)

\begin{tabular}{|c|c|c|c|c|c|c|c|c|}
\hline \multicolumn{2}{|l|}{ РCT 0} & \multicolumn{2}{|l|}{ PCT U } & \multirow[b]{2}{*}{ SE \% } & \multirow[b]{2}{*}{ SP \% } & \multirow[b]{2}{*}{ PPV \% } & \multirow[b]{2}{*}{ NPV \% } & \multirow[b]{2}{*}{$\mathrm{LR}+\%$} \\
\hline PFS O (n) & PFS U (n) & PFS O (n) & PFS U (n) & & & & & \\
\hline 21 & 10 & 0 & 17 & 100,0 & 63,0 & 67,7 & 100,0 & 2,7 \\
\hline
\end{tabular}

PCT: Penile Cuff Test.

PFS: Pressure-Flow Studies.

O: Obstructed.

U: Unobstructed.

$\mathrm{n}$ : Number of patients.

SE: Sensitivity.

SP: Specificity.

PPV: Positive Predictive Value.

NPV: Negative predictive Value.

LR+: Positive Likelihood Ratio. 
introduction of bladder outlet obstruction index (BOOI) and bladder contractility index (BCI).

Thus, PFS represents the gold standard for the evaluation of BPO [1]. Nevertheless, this test is not used as a routine examination before surgery for BPO [19], because it is considered time-consuming, not cost-effective overall [1] and a potential cause of morbidity [21].

Over the last 30 years, no simple tool proved to be reliable in distinguishing between BPO and IDC.

The role of non-invasive UD in clinical practice is still unclear [19] and few data have been published about correlation between PCT and PFS findings $[6,7,22,23]$.

Aim of our study was to make a comparison between PCT and PFS in the diagnostic work-up on patients candidates for TURP: summarizing our results, PCT showed a SE of $100 \%$ and a SP of $63 \%$ in detecting obstructed patients, with a PPV of $68 \%$ and a NPV of $100 \%$.

Overall, the rate of correctly classified patients at PCT was $79 \%$. In particular, non-obstructed patients at PCT were confirmed as non-obstructed at PFS.

Using the nomogram modified for non-invasive pressure measurement, Griffiths et al. [7] obtained with PCT a PPV of $68 \%$ and a NPV of $78 \%$ for PFS diagnosis of BPO. Besides, they noticed that predictive accuracy for obstruction could be improved by the additional criterion of $Q_{\max }$ less than $10 \mathrm{~mL} / \mathrm{s}$, thus obtaining a PPV of $88 \%$ and a NPV of $86 \%$.

In our study, patients categorization into subgroups according to their $Q_{\max }$ (threshold $10 \mathrm{~mL} / \mathrm{s}$ ) did not add any further information as it did not get confirmation of its statistical significance at Fisher exact test.

The difference between Griffiths' and our results could be due to a different selection of patients: in our study, only patients who were candidates for a TURP [24] were enrolled, while in Griffiths' paper the Authors intended to analyze patients complaining with LUTS [7]. Nevertheless, further studies are needed to investigate this aspect.

Our data seem to confirm those ones obtained in another, more recent paper based on 30 consecutive patients complaining with LUTS. In this study, Borrini L et al. [22] found for PCT a PPV of $82 \%$ and a NPV of $88 \%$ for BPO at PFS.

According to our experience, non-invasive UD, in particular PCT, can be a useful diagnostic tool in patients candidates for TURP, suggesting a possible solution to the thorny problem about urodynamic tests before surgery for BPO. In fact, compared to PFS, PCT appeared as a quick and accurate test to rule out a BPO condition because of its high NPV. Thus it could be used to run a selection of non-obstructed patients suspected for an eventual IDC condition. Indeed, such patients are the most critical ones in BPO surgery [25], with some papers reporting about one forth of them showing no symptoms improvement after a surgical treatment $[24,26]$.
In a paper by Harding et al. [27], a consecutive cohort of 208 men undergoing TURP were previously evaluated by PCT: $87 \%$ of patients diagnosed with BPO had a clinical improvement after surgery, while only $56 \%$ of patients deemed as not obstructed had a good outcome.

By such diagnostic pathway, non-obstructed patients (probably with IDC) could be easily recognized and adequately counseled in advance about the prospect of poor or partial symptoms improvement after surgery for $\mathrm{BPO}$, avoiding a PFS.

Furthermore, the rate of correctly classified patients at PCT was high, confirming that most obstructed patients can be adequately evaluated by PCT.

We should also consider that PCT categorization does not allow for 'equivocal' patients, who finally represent the mismatch between the two urodynamic tests. Anyway, those patients can be mostly considered eligible to surgery, so PFS could be neglected in such cases.

Only patients with an unclear diagnosis could be suggested to undergo PFS, while the other ones could be probably evaluated just by PCT, getting the amount of pre-operative information useful both to the surgeon and to the patient, in terms of preoperative counseling.

Limitations of our study are the relatively small sample size and the lack of a post-operative follow-up to assess TURP efficacy in different categories of patients.

On the other hand, this is, to our knowledge, the first study comparing PCT to PFS in patients candidates for TURP.

Further papers on large series of patients including post-operative follow-up are needed, in order to assess the real role of PCT in the pre-operative evaluation for BPO.

\section{Conclusions}

PCT can be an efficient tool in evaluating patients candidates for TURP. In particular, it showed good reliability in ruling out BPO because of its high NPV, with a high rate of correctly classified patients overall. Further studies based on a bigger sample size are needed, including postoperative follow-up.

\section{Competing interests}

The authors declare that they have no competing interests.

\section{Authors' contributions}

DB participated in the design of the study, performed the statistical analysis, reviewed the literature and drafted the manuscript. ADS participated in the design and coordination of the study, performed the urodynamic tests, collected the data. GG participated in the design of the study, collected the data and reviewed the literature. RM collected the data and participated in the coordination of the study. SM participated in the design of the study and reviewed the literature. GV conceived of the study, and participated in its design and coordination. EFA conceived of the study, participated in its design and coordination and the statistical analysis, supervised the draft. All authors read and approved the final manuscript. 


\section{Author details}

'School of Specialization in Urology, University of Rome Tor Vergata, Viale Oxford, 81-00133 Rome, Italy. ${ }^{2}$ NeuroUrology Unit, IRCCS Fondazione Santa Lucia, Rome, Italy. ${ }^{3}$ Department of Experimental Medicine and Surgery, University of Rome Tor Vergata, Rome, Italy. ${ }^{4}$ Neuro-Urology Unit, Careggi Hospital, Florence, Italy.

Received: 25 September 2014 Accepted: 11 December 2014 Published: 19 December 2014

\section{References}

1. Nitti WW: Pressure Flow Urodynamic Studies: The Gold Standard for Diagnosing Bladder outlet Obstruction. Rev Urol 2005, 7(Suppl 6):S14-S21.

2. Mangera A, Osman NI, Chapple CR: Assessment of BPH/BOO. Indian J Urol 2014, 30(2):177-180. doi:10.4103/0970-1591.126902.

3. Blake C, Abrams P: Noninvasive techniques for the measurement of isovolumetric bladder pressure. J Urol 2004, 171(1):12-19.

4. Huang Foen Chung JW, Bohnen AM, Pel JJ, Bosch JL, Niesing R, van Mastrigt R: Applicability and reproducibility of condom catheter method for measuring isovolumetric bladder pressure. Urology 2004, 63:56-60.

5. D'Ancona CAL, Bassani JWM, de Oliveira Querne FA, Carvalho J, Oliveira RR, Netto NR Jr: New method for minimally invasive urodynamic assessment in men with lower urinary tract symptoms. Urology 2008, 71:75-78.

6. Griffiths CJ, Rix D, MacDonald AM: Noninvasive measurement of bladder pressure by controlled inflation of a penile cuff. J Urol 2002, 167(3):1344-1347.

7. Griffiths CJ, Harding C, Blake C, Mclntosh S, Drinnan MJ, Robson WA Abrams P, Ramsden PD, Pickard RS: A nomogram to classify men with lower urinary tract symptoms using urine flow and noninvasive measurement of bladder pressure. J Urol 2005, 174(4 Pt 1):1323-1326.

8. Clarkson B, Griffiths C, McArdle F: Continuous non-invasive measurement of bladder voiding pressure using an experimental constant low-flow test. Neurourol Urodyn 2012, 31:557-563.

9. Drinnan MJ, Mclntosh SL, Robson WA, Pickard RS, Ramsden PD, Griffiths CJ: Inter-observer agreement in the estimation of bladder pressure using a penile cuff. Neurourol Urodyn 2003, 22:296-300.

10. Schafer W, Abrams P, Liao L, Mattiasson A, Pesce F, Spangberg A, Sterling AM, Zinner NR, van Kerrebroeck P, International Continence Society: Good urodynamic practices: uroflowmetry, filling cystometry and pressure-flow studies. Neurourol Urodyn 2002, 21(3):261-274.

11. Abrams P, Cardozo L, Fall M, Griffiths D, Rosier P, Ulmsten U, van Kerrebroeck P, Victor A, Wein A, Subcommittee of the International Continence Society: The standardisation of terminology of lower urinary tract function: report from the Standardistion Sub-committee of the International Continence Society. Neurourol Urodyn 2002, 21:167-178.

12. Griffiths D, Hofner $K$, van Mastrigt R, Rollema HJ, Spangberg A, Gleason D: Standardisation of terminology of lower urinary tract function: pressure flow studies of voiding, urethral resistance and urethral obstruction. Neurourol Urodyn 1997, 6:1-18.

13. Abrams P: Bladder outlet obstruction index, bladder contractility index and bladder voiding efficiency: three simple indices to define bladder voiding function. BJU Int 1999, 84:14-15.

14. Reynard JM, Yang Q, Donovan JL, Peters TJ, Schafer W, de la Rosette JJ, Dabhoiwala NF, Osawa D, Lim AT, Abrams P: The ICS-'BPH' Study: uroflowmetry, lower urinary tract symptoms and bladder outlet obstruction. Br J Urol 1998, 82(5):619-623.

15. Bossuyt PM, Reitsma JB, Bruns DE, Gatsonis CA, Glasziou PP, Irwig LM, Moher D, Rennie D, de Vet HC, Lijmer JG: Standards for Reporting of Diagnostic accuracy. The STARD statement for reporting studies of diagnostic accuracy: explanation and elaboration. Ann Intern Med 2003, 138(1):W1-W12

16. Abrams PH, Griffiths D: The assessment of prostatic obstruction from urodynamic measurements and from residual urine. BJU 1979, 51:129-134.b.

17. Griffiths DJ: Pressure-flow studies of micturition. Urol Clin North Am 1996, 23:279-297.

18. Chancellor MB, Blaivas JG, Kaplan SA, Axelrod S: Bladder outlet obstruction versus impaired detrusor contractility: the role of outflow. J Urol 1991, 145(4):810-812.

19. Oelke M, Bachmann A, Descazeaud A, Emberton M, Gravas S, Michel MC, N'dow J, Nordling J, de la Rosette JJ: Guidelines on the management of male lower urinary tract symptoms, incl. benign prostatic obstruction. Eur Assoc Urol 2013, 8-9.

20. Gerstenberg TC, Andersen JT, Klarskov P, Ramirez D, Hald T: High flow infravesical obstruction in men: symptomatology, urodynamics and the results of surgery. J Urol 1982, 127:943-945

21. Porru D, Madeddu G, Campus G, Montisci I, Scarpa RM, Usai E: Evaluation of morbidity of multi-channel pressure-flow studies. Neurourol Urodyn 1999, 18(6):647-52.22.

22. Borrini L, Lukacs B, Ciofu C, Gaibisso B, Haab F, Amarenco G: Predictive value of the penile cuff-test for the assessment of bladder outlet obstruction in men. Prog Urol 2012, 22(11):657-664

23. Arnolds M, Oelke M: Positioning invasive versus non invasive urodynamics in the assessment of bladder outlet obstruction. Curr Opin Urol 2009, 19(1):55-62.

24. Neal DE, Ramsden PD, Sharples L, Smith A, Powell PH, Styles RA, Webb RJ: Outcome of elective prostatectomy. BMJ 1989, 299(6702):762-767.

25. Losco G, Keedle L, King Q: Non-invasive urodynamics predicts outcome prior to surgery for prostatic obstruction. BJU Int 2013, 112(Suppl 2):61-64.

26. Emberton $\mathrm{M}$, Neal $\mathrm{DE}$, Black $\mathrm{N}$ : The effect of prostatectomy on symptom severity and quality of life. Br J Urol 1996, 77(2):233-247.

27. Harding C, Robson W, Drinnan M, Sajeel M, Ramsden P, Griffiths C, Pickard R: Predicting the outcome of prostatectomy using non-invasive bladder pressure and urine flow measurements. Eur Urol 2007, 52:186-192.

doi:10.1186/1471-2490-14-103

Cite this article as: Bianchi et al:: Correlation between penile cuff test and pressure-flow study in patients candidates for trans-urethral resection of prostate. BMC Urology 2014 14:103.

\section{Submit your next manuscript to BioMed Central and take full advantage of:}

- Convenient online submission

- Thorough peer review

- No space constraints or color figure charges

- Immediate publication on acceptance

- Inclusion in PubMed, CAS, Scopus and Google Scholar

- Research which is freely available for redistribution 